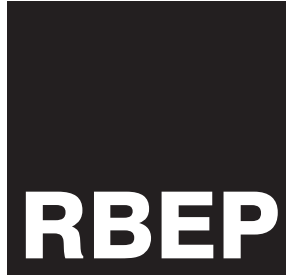

\section{Juventudes populares em um pré-vestibular: a construção coletiva de expectativas e campos de possibilidades educacionais*}

Rodrigo Pereira da Rocha Rosistolato

Jose Abdalla Helayël-Neto

Marcel Duarte da Silva Xavier

\section{Resumo}

Apresenta as narrativas de estudantes oriundos das camadas populares sobre suas expectativas de inclusão no ensino superior. A metodologia utilizada mescla observações etnográficas, entrevistas e aplicação de questionários. A pesquisa foi realizada durante o único pré-vestibular popular da cidade de Petrópolis, região serrana do Estado do Rio de Janeiro. Ao todo, 46 estudantes da turma de ingressantes de 2008 responderam ao questionário, composto por questões abertas, sobre as justificativas deles para a opção por aquele pré-vestibular popular e as representações sobre as profissões escolhidas. São discutidos, então, a construção coletiva de expectativas, os campos de possibilidades educacionais mapeadas durante as observações realizadas e a análise das narrativas presentes nos questionários.

Palavras-chave: juventudes; educação; ensino superior; desigualdades educacionais.

* Uma versão deste texto, com acréscimos, foi apresentado com o título "Juventudes populares: limites e possibilidades de acesso ao ensino superior" no XXVIII Congresso Internacional da Associação Latino-Americana de Sociologia, realizado na cidade do Recife, em 2011. 


\section{Abstract \\ Popular youth in a "pré-vestibular": the collective construction of expectations and educational possibility fields}

The article presents the narratives of students from the lower classes about their expectations of inclusion in higher education. The methodology used blends ethnographic observations, interviews and questionnaires. The investigation was conducted in the only popular "pré-vestibular" of the city of Petropolis, mountain region of the State of Rio de Janeiro. In all, 46 students from the beginner class of 2008 answered the questionnaire, consisting of open questions which sought to understand, among other topics, the justifications for the choice of that popular "pré-vestibular" and the representations of the chosen professions. Here, we discuss the collective construction of expectations and possibilities of educational fields mapped during the observations and analysis of the narratives presented in these questionnaires.

Key words: Youth, education, higher education, educational inequalities.
${ }^{1} \mathrm{~A}$ pesquisa foi coordenada pelo físico José Abdalla Helayel-Netto - Centro Brasileiro de Pesquisas Físicas (CBPF) - e recebeu apoio do Conselho Nacional de Desenvolvimento Científico e Tecnológico (CNPq) com a concessão de uma bolsa de iniciação científica.

${ }^{2}$ Para o debate sobre a categoria juventude, ver Bourdieu (1983), Minayo et al. (1999), Groppo (2000), Paim (2002) Novaes (2003), Pais (2003), Kell (2004), Sposito (2005), Rosistolato (2009a, 2009b)

${ }^{3}$ Para a noção de capital cultural ver Bourdieu (2004, 2001).

\section{Introdução}

Este artigo foi elaborado com base nos dados da pesquisa "Juventudes populares e projetos de escolarização de nível superior" ${ }^{1}{ }^{1}$ O projeto foi pensado com base em dois objetivos complementares: analisar as metodologias de ensino de ciências utilizadas em um pré-vestibular comunitário e mapear os sentidos da educação escolar presentes entre estudantes pertencentes às camadas populares, residentes em periferias urbanas da cidade de Petrópolis, região serrana do Estado do Rio de Janeiro. Como a residência em periferias urbanas não pressupõe, necessariamente, o pertencimento às camadas populares, a definição dos conceitos utilizados torna-se fundamental para a descrição da pesquisa, porque é necessário especificar o ponto de vista orientador da seleção dos jovens.

O trabalho privilegia o discurso de jovens ${ }^{2}$ residentes em periferias urbanas, oriundos de famílias com baixo poder aquisitivo e reduzido capital cultural. ${ }^{3}$ O perfil traçado corresponde ao proposto por Zago (2006) para a reflexão sobre os jovens pobres já inseridos no sistema superior de ensino. A autora analisa estudantes egressos de pré-vestibulares populares, acompanha as experiências de inserção na cultura universitária e relativiza a ideia de que o acesso à universidade seria a chave para a redução das desigualdades educacionais relacionadas ao ensino superior.

A utilização dos termos periferia ou periferias urbanas não é apenas uma referência à divisão do espaço topográfico que marca as distâncias 
físicas entre o centro e as periferias das cidades. Trata-se de uma categoria analítica, inspirada no trabalho de Norbert Elias e John Scotson (2000), que analisam uma periferia urbana onde relações de hierarquia e dominação se consolidam entre pessoas "objetivamente" iguais, quando comparadas com base na posição social e no território ocupado. Os conflitos presentes naquele contexto eram independentes de variáveis "objetivas" como classe, sexo, cor da pele, idade, o que permite discutir as desigualdades presentes entre grupos aparentemente iguais.

A referência ao trabalho de Elias e Scotson (2000) se deve ao entendimento de que a palavra periferia, embora agregue múltiplos significados, quando utilizada como categoria política, tende a homogeneizar pertencimentos identitários e singularizar vivências plurais. Sua presença em arenas de debate sobre questões relativas à composição das cidades e às populações supostamente marginalizadas pode reduzir a experiência cotidiana nesses contextos à ausência de direitos sociais. Aqui, pretende-se problematizar tais visões com base na observação das experiências juvenis relacionadas à cultura escolar. Acreditamos que, da mesma forma que as variáveis objetivas não explicavam as desigualdades sociais presentes no contexto analisado pelos autores, a ideia singular de populações marginalizadas não explica a pluralidade de expectativas e formas de estar no mundo presentes nas periferias urbanas.

A universalização da educação básica é recente no Brasil. Faz parte de um projeto de nação orientado pela expectativa de transformação da escola em espaço de construção da igualdade. De acordo com a Pesquisa Nacional por Amostra de Domicílio (Pnad) de 2007, 97,6\% da população com idade entre 7 e 14 anos já estava na escola (Ribeiro; Koslinski, 2008). Os números são positivos, mas não podem ser analisados como sinônimo de qualidade da escola. Existe algum consenso no campo educacional sobre as vantagens da universalização e dos desafios trazidos por ela. Antes, a inexistência de escolas era o foco; atualmente, a qualidade do ensino parece ser o principal desafio.

Nesse sentido, é necessário salientar que a escola, mesmo universalizada, fora criticada como lócus da reprodução de desigualdades sociais, principalmente quando o escopo de suas ações são grupos sociais pertencentes às camadas populares. Ribeiro e Koslinski (2008) identificam três gerações nas análises sobre a relação entre escola, igualdade e mobilidade social. Enquanto a primeira geração enfatizou a impossibilidade de a escola reverter desigualdades socioeconômicas preexistentes entre os alunos, a segunda demonstrou que a escola pode fazer a diferença nos resultados escolares. Os autores percebem a consolidação de uma terceira geração que visa conjugar as abordagens da sociologia da educação às da sociologia urbana.

A terceira geração de estudos identificada por Ribeiro e Koslinski (2008) parte da hipótese de que a organização social do território produz efeitos sobre as condições efetivas de escolarização de crianças e de jovens. Há trabalhos desenvolvidos com base nessa premissa que permitem refletir sobre o cenário educacional apresentado a jovens residentes em periferias urbanas que desejam se apropriar dos saberes oferecidos pelas 
${ }^{4}$ As avaliações nacionais são realizadas pelo Sistema de Avaliação da Educação Básica (Saeb/ Prova Brasil). O Estado do Rio de Janeiro realiza as avaliações pelo Sistema de Avaliação da Educação Básica do Estado do Rio de Janeiro (Saerj) e o Município do Rio de Janeiro tem por base a Prova Rio

${ }^{5} \mathrm{O}$ mesmo pré-vestibular foi campo de pesquisa para outras temáticas. Ferreira (2007) realizou uma investigação na qual discutiu as concepções de justiça social e desigualdade presentes em movimentos populares que utilizam a educação como instrumento coletivo de mudança social.

${ }^{6}$ O curso foi fundado em 1994 , como um núcleo do Pré-Vestibular para Negros e Carentes (PVNC) e ainda mantém relações com outros núcleos e com a coordenação geral do movimento. No entanto, guarda especificidades que o distinguem dos outros núcleos: a principal é a ampliação da disciplina "cultura e cidadania", desenvolvida em todos os cursos do PVNC, com a inclusão do debate sobre ciência na sociedade brasileira. Em Petrópolis, a disciplina, atualmente, é organizada em torno de três temáticas: "ciência, cultura e cidadania". escolas para a consolidação de seus projetos de vida. Nos casos do Rio de Janeiro (Alves; Franco Júnior; Ribeiro, 2009), de São Paulo (Torres et al., 2008) e de Belo Horizonte (Soares; Rigotti; Andrade, 2009), guardadas as especificidades da organização espacial de cada cidade, a relação entre segregação residencial e desigualdade escolar é recorrente. Escolas localizadas em periferias urbanas ou em favelas tendem a produzir resultados inferiores quando comparadas àquelas localizadas em regiões centrais. Especificamente no Rio de Janeiro, estudantes residentes em favelas correm maior risco de enfrentar distorção idade-série e evasão escolar.

O foco das pesquisas orientadas pelos pressupostos da terceira geração de estudos tem sido as relações entre os estudantes e as escolas que fornecem educação básica. A ênfase recai sobre a transmissão da cultura escolar e sua recepção, medida por meio dos resultados obtidos por estudantes em testes padronizados, aplicados durante as avaliações nacionais e locais. ${ }^{4} \mathrm{O}$ corpo discente é o escopo e a principal medida de eficácia das políticas públicas voltadas para a equalização das oportunidades e a consequente diminuição das desigualdades educacionais.

Os resultados indicam que trajetórias de escolarização em escolas públicas e periféricas impedem ou atrapalham a consolidação dos saberes considerados básicos, inclusive para a superação do vestibular das universidades públicas. Cabe perguntar o que ocorre quando estudantes formados no sistema público desejam utilizar o capital escolar adquirido durante a educação básica para orientar suas ações posteriores, direcionadas para o acesso ao ensino superior. Quais as representações sobre a educação escolar adquirida durante a formação básica? Quais as dificuldades e as estratégias escolhidas para a inserção no ensino superior? Quais as possibilidades de inserção no universo simbólico da academia? Quais as escolhas possíveis no campo de possibilidades de formação profissional?

O projeto de pesquisa que deu origem a este artigo foi pensado com base nessas questões. A cidade de Petrópolis foi escolhida porque os pesquisadores têm inserção consolidada no único pré-vestibular popular em atividade no município. ${ }^{5}$ Trata-se de um movimento popular organizado com o objetivo de contribuir com a preparação de jovens pobres que desejam prestar vestibular para o sistema público de ensino superior. ${ }^{6}$ Além disso, entendemos que a análise das trajetórias de estudantes pobres que desejam estudar em universidades públicas e residem em uma cidade onde elas não existem permite ampliar as reflexões sobre a temática. Os estudantes analisados têm uma barreira extra a superar: depois da aprovação, precisam se organizar para encontrar meios de subsistência em contextos não alcançados por suas redes de solidariedade familiar.

A metodologia utilizada é qualitativa, composta por observações etnográficas, realização de entrevistas e aplicação de questionários. A opção por questionários ocorreu devido à identificação da intensa circulação de estudantes. Trata-se de um pré-vestibular popular, administrado por e para jovens pobres, egressos de escolas públicas. Funciona aos finais de semana e feriados e atende a um número reduzido de estudantes porque 
recebe apenas uma turma por ano letivo. Não foi possível, até o momento, elaborar estatísticas da circulação dos estudantes, pois mesmo aqueles que abandonam as aulas por longos períodos retornam às vésperas do vestibular ou comparecem esporadicamente.

O grupo de pesquisa aplicou 46 questionários na turma de ingressantes de 2008. O questionário foi construído com o objetivo de mapear o perfil socioeconômico e cultural dos estudantes, suas trajetórias escolares e a relação com os saberes disciplinares, as justificativas para a escolha do pré-vestibular e as expectativas de inserção no ensino superior. O que se pretende, neste artigo, é analisar as justificativas da opção por um pré-vestibular popular e discutir as representações sobre as profissões escolhidas. A questão se justifica porque se acredita que os estudantes pobres buscam cursos populares simplesmente por serem gratuitos. A pesquisa, no entanto, indica que, embora a gratuidade seja importante, há outros elementos que fazem com que os jovens escolham, especificamente, aquele pré-vestibular para estudar. É possível identificar, com base nos dados, algumas questões relacionadas à cultura da cidade de Petrópolis e ao lugar ocupado por esse movimento social nas representações sobre o campo de possibilidades ${ }^{7}$ de acesso ao ensino superior, presente no horizonte dos estudantes. As carreiras escolhidas também põem em evidência representações sobre as profissões de nível superior e as dimensões valorativas relacionadas à inserção na universidade.

\section{O olhar sociológico sobre a escola e os sistemas educacionais}

A relação das camadas populares com a escolarização tem sido objeto privilegiado nas análises realizadas pela sociologia da educação. Dandurand e Ollivier (1991) apontam o período de 1945 a 1965 como o momento da institucionalização desse campo do conhecimento. De acordo com os autores, durante o pós-guerra consolida-se um projeto de redistribuição de vantagens sociais e riquezas por meio de mecanismos coordenados pelo Estado. A educação se apresenta como um desses mecanismos e os sistemas educacionais são pensados como elementos associados ao desenvolvimento econômico. Nogueira (1990) também indica as décadas de 1950 e 1960 como o momento de constituição e estabelecimento da sociologia da educação como um campo de pesquisa. A autora afirma que, nos países industrialmente mais desenvolvidos, inclusive, houve aumento significativo de pesquisas com o objetivo de conhecer a população escolar e os sistemas escolares estabelecidos.

No período analisado pelos autores, a racionalidade e o crescimento racionalmente planejado se estabelecem como conceitos centrais na gestão das sociedades, o que colabora com a construção de uma visão de mundo que relaciona escolarização a um duplo papel: superação do atraso econômico e construção de sociedades justas (meritocráticas), modernas e democráticas. Freitag (1986) indica que à escola pública e gratuita era conferido o poder de resolver o problema do acesso à educação,

\footnotetext{
${ }^{7}$ Para o debate sobre as noções de "projeto" e "campo de possibilidades", ver Velho (1999).
} 
${ }^{8}$ A pesquisa que deu origem ao relatório Coleman recebeu financiamento do governo americano. Foi realizada com uma amostra de 645 mil alunos e tinha por objetivo geral estudar em que medida diferenças de "raça", sexo, origem geográfica e origem social afetavam o desempenho escolar. Coleman demonstrou que as variáveis socioeconômicas explicam melhor as diferenças de desempenho do que as variáveis intraescolares (Bonamino; Franco, 1999). Para a crítica às análises realizadas por Coleman, ver Willms (2010).

${ }^{9}$ Pierre Bourdieu tem uma contribuição vasta no campo da educação. Neste texto, faremos referência, especificamente, aos trabalhos publicados nos livros: A reprodução (1975), Escritos de educação (2001) e A economia das trocas simbólicas (2003). garantindo o princípio da igualdade de oportunidades entre todos os cidadãos. Acreditava-se que os sujeitos competiriam em um contexto de igualdade e os destaques seriam determinados por dons individuais. A formação escolar, nesse momento, era vista como alavanca de crescimento econômico, instrumento de equalização das oportunidades e redistribuição de bens e serviços.

Nessa perspectiva, a escola seria uma instituição neutra, difusora de um conjunto de conhecimentos organizados racionalmente, com base em critérios coletivistas e avessos a qualquer privilégio tradicional. A seleção dos alunos aconteceria por intermédio de critérios racionais, que valorizariam os dons individuais. Os sistemas educacionais eram pensados como espaços livres de influências relacionadas a posições de classe ou quaisquer outros demarcadores de origem social.

A crítica a esse modelo de mundo surge nos anos 1960, com a divulgação de uma série de pesquisas financiadas pelos governos inglês, americano e francês. Todas as análises indicaram influências da origem social sobre os destinos escolares. Bonamino e Franco (1999) afirmam que o relatório Coleman ${ }^{8}$ teve papel fundamental ao demonstrar que as diferenças de desempenho deveriam ser explicadas em função de variáveis socioeconômicas e não, exclusivamente, em termos de variáveis intraescolares. A estrutura do sistema escolar americano não possuía o grau de neutralidade imaginado e as diferenças de desempenho não poderiam ser explicadas como reflexo de dons individuais. Os autores também indicam que os resultados encontrados na França e na Inglaterra são compatíveis com os apresentados por Coleman nos Estados Unidos da América.

Desde a publicação desses relatórios nacionais, as expectativas positivas relacionadas à contribuição dos sistemas educacionais para a diminuição das desigualdades sociais foram relativizadas, de forma que o consenso sobre os resultados da ampliação dos sistemas de ensino foi problematizado. As pesquisas demonstraram que as desigualdades existentes entre as classes sociais se manifestam nos contextos escolares, criando dissonâncias entre as expectativas de professores e estudantes com relação aos processos educativos. Em síntese: estudantes oriundos de classes sociais que tradicionalmente valorizam a educação tendem a se adaptar com mais facilidade aos contextos de ensino porque dominam os códigos linguísticos necessários à participação naquele espaço. Por outro lado, estudantes de classes sociais que tradicionalmente não se relacionam com a educação formal enfrentam dificuldades de adaptação aos modelos implementados pela escola.

Os relatórios provocaram mudanças epistemológicas significativas no campo dos estudos em sociologia da educação e transformações no campo político, visto que comprovaram que a instituição escolar não teria capacidade para eliminar as desigualdades sociais de origem. É nesse momento que as teses apresentadas por Bourdieu ganham notoriedade, porque criticam as visões da escola como transformadora e democratizadora das sociedades. ${ }^{9}$ 
Os trabalhos de Bourdieu se inserem nas "teorias da reprodução cultural" (Nogueira, 1990) e podem ser, inclusive, classificados como um dos alicerces dessa proposta teórico-metodológica. Nela, os sistemas escolares são vistos como alguns dos principais responsáveis pela manutenção e legitimação de privilégios sociais. A própria ideia de dons individuais é radicalmente negada nesse modelo. Bourdieu entende que a educação propicia aos indivíduos um corpo comum de categorias de pensamento que tornam a comunicação possível em contextos onde vige a cultura escolar. Os sistemas de ensino tendem a oferecer um programa homogêneo de percepção, de pensamento e de ação; um recorte da cultura geral onde são selecionados os elementos considerados mais legítimos. A consequência lógica do processo seria a homogeneização dos indivíduos inseridos nos sistemas educacionais. Porém, a simples inserção não determina a homogeneização, porque a incorporação das categorias de pensamento utilizadas nos sistemas escolares depende do domínio prévio das mesmas categorias ou dos modelos de reflexão necessários ao seu entendimento. Assim, a escola acaba por impor os conteúdos considerados mais legítimos a todos os estudantes, sem considerar as diferenças de origem social.

O sistema escolar, diz Bourdieu, parte do pressuposto de que os alunos são indivíduos abstratos que poderiam competir em condições igualitárias na escola. O autor entende que, ao contrário, os alunos trazem uma bagagem cultural, relacionada à sua origem social, que pode ser mais ou menos rentável no mercado escolar. A referência à existência de um mercado permite dizer que o sucesso não é somente o resultado de dons individuais; ele é fruto de acúmulo prévio de capital cultural, que faz com que estudantes privilegiados compreendam com mais facilidade a cultura escolar oferecida pela escola.

Bourdieu propõe uma relação direta entre contextos familiares e aprendizado escolar. É o capital cultural familiar, herdado e incorporado pelos filhos, que proporciona maiores níveis de aprendizagem. Por mais que, conforme Almeida (2007), a família, nas sociedades modernas, tenha perdido o poder de monopólio da definição dos conteúdos de socialização de seus filhos - porque é obrigada a partilhá-la com a escola, se é possível dizer que a cultura escolar é um recorte da "cultura legítima" -, quanto mais integrada à cultura "legítima" é a família, maior será a probabilidade de seus filhos obterem sucesso no mercado escolar. O capital cultural herdado pelas crianças reduz as distâncias simbólicas existentes entre o universo familiar e o escolar. Em contrapartida, quanto menos integradas à "cultura legítima", maior a distância entre as famílias e a escola.

Há, no entanto, gerações de pesquisa posteriores que se dedicam a abrir a "caixa-preta" das escolas e buscar elementos para pensar se e quando a escola pode fazer a diferença. Os estudos sobre "escolas eficazes" e "efeito escola" passaram a propor que estas poderiam combater os efeitos das desigualdades econômicas e culturais presentes entre as classes nos processos de escolarização. ${ }^{10}$ Portanto, enquanto a primeira geração de estudos em sociologia da educação enfatizou a impossibilidade de a escola reverter desigualdades socioeconômicas preexistentes entre
${ }^{10}$ Para este debate, ver Konstantopoulos e Borman (2011) e Willms (2010). 
os alunos, a segunda enfatizou que a escola pode fazer a diferença nos resultados escolares. E há a terceira geração, já identificada por Ribeiro e Koslinski (2008, 2009), que visa conjugar as abordagens da sociologia da educação às da sociologia urbana. O foco das pesquisas realizadas pela terceira geração tem sido as relações entre a organização social do território e a produção social de escolas com qualidade.

\section{Análise sociológica da educação no Brasil}

As análises das relações entre as classes populares e a cultura escolar no Brasil também podem ser vistas como resultado da consolidação desse campo de estudos. Elas têm privilegiado as dificuldades enfrentadas por estudantes pobres na educação básica (Rocha; Perosa, 2009; Lavinas; Barbosa, 2000); a relação entre segregação residencial e desigualdades educacionais (Alves; Franco Junior; Ribeiro, 2008); o prestígio escolar entre camadas populares (Costa, 2008; Costa; Koslinski, 2006); o prolongamento da escolarização e as novas formas de desigualdades sociais (Zago, 2007); a relação entre desempenho escolar, gênero e raça (Carvalho, 2003, 2001); entre outros temas. Esses estudos privilegiam objetos específicos: a escola e a visão sobre esta dos atores sociais que a compõem, além do discurso daqueles que pertencem à intelligentsia formada para pensar sobre o fenômeno educacional. O crescimento da sociologia da educação tem sido significativo e as interfaces com temas clássicos da sociologia e da antropologia permitem reflexões substanciais sobre a realidade social brasileira e as expectativas relacionadas à educação. ${ }^{11}$

A legislação brasileira classifica o ensino fundamental como obrigatório para a população em geral: independentemente de crença religiosa, sexo, cor ou posição social, crianças e adolescentes em idade escolar têm de estar na escola. Os sistemas escolares visam à distribuição igualitária de oportunidades de escolarização, mas não impedem a construção e a circulação de representações sobre as escolas individualmente e do sistema como um todo. Também não conseguem romper com lógicas de organização que hierarquizam as escolas e geram expectativas diferentes com relação à possibilidade de estas contribuírem com a modificação de trajetórias e destinos sociais. Entre as camadas populares, há grupos que desvalorizam a escola como espaço de formação e outros que a percebem como instituição fundamental para a formação de seus filhos.

Costa (2008) realizou uma pesquisa sobre o significado social da escola entre as camadas populares e percebeu a construção de hierarquias que supervalorizam e sobrevalorizam escolas do sistema municipal de

${ }^{11} \mathrm{O}$ crescimento deste debate ocorre, principalmente, em programas de pós-graduação em educação. Não é possível dizer o mesmo sobre os programas de pós-graduação em ciências sociais. Para este debate, ver Costa e Nogueira (2009); Costa e Silva (2003); Silva (2001) educação do Rio de Janeiro, criando um gradiente de prestígio entre as unidades escolares. O autor indica que o prestígio das escolas constrói, tanto no plano das representações quanto no das práticas sociais, diferenças significativas entre instituições pertencentes à mesma rede pública de ensino. Enquanto algumas são disputadas por pais e mães que desejam oferecer o que consideram uma boa educação para seus 
filhos, outras são estigmatizadas como depósitos de crianças e renegadas pela população, que as percebe como última alternativa. O autor aponta que a análise das diferenças entre as escolas mais e menos prestigiadas permite perceber a presença de um tipo de elite entre estudantes que, tecnicamente, seriam iguais por pertencerem à mesma rede de ensino e, acrescente-se, à mesma camada social.

As diferenças de desempenho entre escolas que atendem ao público pertencente às camadas populares indicam a pluralidade e a diversidade de sentidos atribuídos à educação escolar garantida pelo Estado. É possível relativizar algumas ideias como rede de ensino, sistema de ensino e sua relação com a distribuição igualitária de educação. O foco da pesquisa realizada por Costa (2008) é o ensino fundamental, mas talvez seja possível ampliar as conclusões para o ensino médio.

A conclusão da educação básica pressupõe algum grau de homogeneidade escolar entre os jovens egressos. Porém, como a pesquisa de Costa (2008) revela, há hierarquias de prestígio entre as escolas que compõem redes de ensino, o que permite deduzir que há também significativas diferenças na formação dos estudantes que acessam escolas com maior ou menor prestígio. O diploma de conclusão do ensino médio habilita os egressos para os concursos nacionais de acesso ao ensino superior público e também para as seleções promovidas pelas universidades privadas. Com base na pesquisa (Costa, 2008), é possível dizer que estudantes formados em escolas públicas de pouco prestígio, além de enfrentarem alunos recém-saídos de escolas particulares, terão de disputar com egressos do mesmo sistema, mas melhor preparados, porque foram formados em escolas públicas de maior prestígio. Percebe-se um processo de estratificação no qual os egressos de escolas públicas de pouco prestígio ocupam as posições menos privilegiadas e têm seus campos de possibilidades reduzidos. Em alguns casos, precisam começar a aprender no momento em que saem da escola, iniciando um novo processo de escolarização, dessa vez fora dela.

\section{Escolarização depois da escola?}

As pesquisas citadas focalizam os processos educacionais realizados em espaços formais, legalmente habilitados a fornecer educação para crianças, adolescentes e jovens. Há, no entanto, processos educacionais que se desenvolvem sem qualquer relação direta com a legislação educacional brasileira. São espaços de formação onde nenhum estudante ou professor tem qualquer obrigação de permanência; também não fornecem diplomas ou certificados e não podem ser utilizados em currículos ou concursos públicos. Porém, têm dois objetivos articulados: contribuir para que estudantes pobres sejam aprovados no vestibular das universidades públicas brasileiras e, como consequência lógica, combater as desigualdades de acesso ao ensino superior no Brasil. Embora não sejam formais, dialogam com o sistema porque (re)ensinam os conteúdos que deveriam ter sido aprendidos na educação básica. 
São muitas as diferenças entre esses espaços de formação e as escolas de ensino fundamental e médio. Não existem provas, notas, listas de presença, aprovação, reprovação, currículo mínimo, e em alguns casos não há sequer uma estrutura que lembre uma sala de aula. Os professores não são obrigados a cumprir nenhum programa, os estudantes não são obrigados a realizar nenhuma tarefa e não estão sujeitos a sanções caso não frequentem as aulas. Os objetivos manifestos por professores e coordenadores são a preparação dos alunos para o vestibular, a contribuição para a democratização do acesso ao ensino superior e a defesa de uma posição política sobre esse acesso e o enfrentamento das desigualdades sociais.

A consolidação dos objetivos depende, basicamente, do trabalho dos professores e coordenadores e do esforço individual dos estudantes para a superação dos déficits educacionais trazidos dos ensinos fundamental e médio. O vestibular é apresentado como uma barreira a ser vencida individualmente, e categorias como "responsabilidade individual", "superação", "independência" e "individualização" são utilizadas para incentivar os estudantes a assumirem sua formação como um projeto de vida individual.

Mas qual seria a relação entre as pesquisas em sociologia da educação e os pré-vestibulares populares? Esses movimentos não são espaços formais de educação e seria muito complicado produzir estatísticas de sucesso ou fracasso escolar com base em sua análise, porque uma das características principais dos movimentos é a rotatividade de alunos e professores. Porém, é possível dizer que os cursos de pré-vestibular trabalham com o resultado final dos processos formais de educação. Os estudantes são jovens que passaram todo o período de escolarização formal inseridos no sistema público e trazem dificuldades que os professores identificam genericamente como "primárias".

Mesmo assim, há sucessos individuais marcados pela superação do vestibular e conclusão de cursos de graduação e pós-graduação. Acreditamos que a reflexão sobre esse modelo de educação fora da escola pode contribuir com o debate sobre os sistemas formais de escolarização. A análise das representações sobre a escola e o que ela pode oferecer, apresentadas por jovens que mesmo tendo clareza da precariedade de sua formação básica decidem potencializar seu capital escolar para dar sequência aos estudos no nível superior, indica que os sistemas formais de escolarização, mesmo precários, conseguem criar expectativas de escolarização de longa duração.

\section{Justificativas para a escolha do pré-vestibular popular}

Antes de iniciar a exposição das justificativas apresentadas pelos estudantes, é necessário dizer que havia 30 entrevistados do sexo feminino e 16 do sexo masculino. Nem todos tinham concluído o ensino médio: 12 estavam no $3^{\circ}$ ano e 2 ainda no $2^{\circ}$ ano. Os estudantes que não tinham terminado o ensino médio eram minoria, porque o movimento privilegia jovens que tenham concluído essa fase de escolarização. A exceção 
sustenta-se no fato de os alunos em fase de conclusão também poderem ser classificados no perfil estabelecido pela coordenação para admissão. Todos são oriundos de famílias com baixa escolarização e baixo capital cultural, possuem renda familiar inferior a três salários mínimos, são egressos de escolas públicas e, na maioria dos casos (42), os primeiros de suas famílias com possibilidades de disputar o vestibular.

O questionário indagava sobre os motivos que orientavam sua opção pela continuidade dos estudos e, especificamente, pela frequência a um pré-vestibular popular. Uma hipótese guiou a formulação do questionário: acreditávamos que não somente questões financeiras stricto sensu faziam com que os jovens buscassem esse espaço de formação. A hipótese foi confirmada em parte porque, embora as questões financeiras tenham presença marcante nas falas dos estudantes, há outras expectativas sustentadas pela legitimidade desse pré-vestibular na cidade de Petrópolis. Os jovens enfatizaram o reconhecimento do curso, a capacitação dos professores e a "ideologia do curso" como as principais bases orientadoras de suas decisões.

A reputação do curso em Petrópolis foi construída nos últimos 16 anos por meio da veiculação de matérias na mídia local e por visitas realizadas anualmente aos colégios estaduais durante o período de inscrições. Seu reconhecimento, no entanto, deriva da construção de redes de solidariedade entre professores, ex-estudantes e familiares, que, além de contribuírem na divulgação, incentivam outros jovens a ingressarem no curso. Há casos em que irmãos, primos e amigos de infância e/ou de escola procuram a coordenação do curso orientados por seus parentes ou amigos que estudam ou estudaram no mesmo espaço e, em alguns casos, se encontram na universidade. Essas redes se mantêm durante o período de formação e contribuem para a permanência dos estudantes, principalmente os mais pobres. A fala de um dos alunos exemplifica esse processo. Ele diz: "[conheci o pré-vestibular] porque minha mãe falou e elogiou tanto o curso que acabei me interessando e vim conhecer e adorei".

Esse caso não foi o primeiro em que adultos, como a mãe do entrevistado, buscaram o pré-vestibular para retomar os estudos. Há, inclusive, alguns casos que passaram a fazer parte da memória do curso, como o de uma senhora com mais de 60 anos, mãe de um professor de história, que concluiu os estudos supletivos com o apoio dos professores do curso, prestou vestibular, passou, concluiu a graduação e atua como psicóloga na cidade de Petrópolis. Há também uma assistente social que, depois de formada, trabalhou com as novas turmas até assumir um cargo na prefeitura da cidade. Essas histórias individuais são contadas e recontadas a cada ano com o objetivo de incentivar os estudantes recém-chegados a permanecerem até o final do curso e enfrentarem o vestibular.

As histórias individuais e coletivas transcendem os espaços do curso e são difundidas entres estudantes e não estudantes de forma que alguns candidatos justificam suas opções com respostas genéricas, como: "fiquei sabendo", "ouvi falar", "todo mundo fala". Algumas entrevistas expressam esse tipo de construção, quando informam que: 
Segundo fiquei sabendo que o trabalho que o grupo faz é ótimo e seria o ideal para tentar uma universidade federal.

Porque várias pessoas que eu conheço estão na universidade.

Pela referência que se tem dele.

Esse reconhecimento se estende aos professores. O corpo docente é flutuante, mas há alguns que podem ser classificados como permanentes. Um dos mais reconhecidos trabalha no curso desde a primeira turma. É um profissional com sólida formação em sua área, que atua no sistema nacional de pós-graduação em ciências exatas e dedica parte de seu tempo ao trabalho em cursos alternativos. Os estudantes reconhecem a titulação dos professores, mas salientam, principalmente, o modelo de relação professor/aluno estabelecido no curso. Estas são as justificativas de três estudantes para a escolha do curso:

Por causa das condições que são boas e os professores são muito atenciosos e porque eu já conhecia pessoas que já estudavam aqui e que falam muito bem.

Porque ouvi muitas coisas boas sobre este curso e também que a taxa de aprovados é muito grande, não só pelo esforço de quem estuda aqui, mas também pela dedicação dos professores.

Porque achei que é muito legal o trabalho dos professores e importante para as pessoas menos favorecidas.

A "ideologia" do curso é o terceiro elemento citado como orientador das escolhas. Optamos por manter o termo entre aspas por tratar-se de categoria nativa. No decorrer da observação, foi possível perceber a veiculação de slogans como "nossa ideologia é", "essa é a ideologia do curso", "precisamos manter nossa ideologia". Em cada caso, o termo ganha significados bastante peculiares, inclusive quando relacionado a mudanças de comportamento. Ao mesmo tempo que alguns estudantes afirmam ter gostado da "ideologia do curso", explicam que desejam mudar suas vidas e suas perspectivas com relação à educação de nível superior e o futuro. Dizem que sabiam que o curso teria a capacidade de mudar suas vidas. Algumas falas expressam essa interpretação.

Desde o inicio do ensino médio, estava preocupado em fazer um prévestibular, fiz algumas pesquisas e iria fazer no pré do Dom Pedro II, contudo, vi que o PVNC mudaria minha vida a partir do dia da palestra de apresentação, pois não é apenas um curso e sim família onde cada um vencerá com o próprio esforço, mas a evolução acontece através do compartilhamento de conhecimentos.

Porque o PVNC não me prepara apenas para o vestibular, mas também para a vida.

Porque quero continuar e trilhar meu caminho para a vida de grande sucesso. 
Após a primeira palestra me fez entender que seria um movimento que acreditaria nos meus ideais, ajudando-me a construir um futuro melhor.

As falas permitem afirmar que, embora todos os estudantes sejam pobres, não escolheram o curso exclusivamente porque não teriam como pagar qualquer outro pré-vestibular. A reputação do movimento como um todo e das pessoas que o compõem é um elemento definidor de projetos individuais sustentados pela crença de que é possível superar deficiências de escolarização por meio da inserção em um espaço coletivo de formação.

A coordenação, os estudantes e os professores veteranos contribuem com a construção dessa representação sobre o curso. As memórias do movimento e das pessoas que obtiveram sucesso no ensino superior sustentam narrativas mistas nas quais o incentivo à superação individual, vista como vitória coletiva, se transforma em elemento de sustentação de um discurso homogêneo que privilegia o processo de formação em detrimento do resultado final. Há, é claro, a expectativa de que todos passem no vestibular, mas a possibilidade de estabelecer contato com a produção de conhecimento científico, ao invés da formação massificada oferecida por outros cursos de pré-vestibular, é enfatizada por todos os professores, inclusive aqueles que também ministram aulas em cursos pagos. Quando indagado sobre os motivos que o levavam a ensinar no curso, um dos professores entrevistados, que também dá aulas em cursos pagos, afirmou que "a primeira motivação é estar participando de algo que pode mudar a vida das pessoas. Essa é a primeira motivação. Mas também, poder falar sobre física para pessoas que querem ouvir sobre física". ${ }^{12}$

A oposição estudante/professor ganha novos significados nos pré-vestibulares populares. Alguns professores são ex-alunos que conseguiram aprovação e passaram a dar aulas, outros são professores do ensino superior que acreditam na capacidade do curso em formar bons pré-universitários. Há também professores da rede pública, em alguns casos convidados por seus ex-alunos. ${ }^{13}$ Todos são voluntários e entendem que a estrutura do pré-vestibular é diferente de uma escola, o que permite relações menos verticalizadas entre alunos e professores. Os docentes, inclusive, apresentam com orgulho os ex-alunos que passaram a ser professores quando iniciaram a graduação. Essas biografias individuais são citadas como exemplos de sucesso e inseridas na biografia coletiva do pré-vestibular. Assim, a memória coletiva do curso, no sentido proposto por Halbwachs (1990), é construída diariamente por aqueles que permanecem como professores e também por outros que obtém sucesso no vestibular, não retornam, mas são apresentados como exemplos de sucesso.

\section{Universidades e carreiras pretendidas}

Os estudantes que escolhem o curso de pré-vestibular alternativo são, de certa forma, homogêneos com relação à situação socioeconômica. Todos possuem renda familiar bruta inferior a três salários mínimos, ${ }^{14}$ são

\footnotetext{
${ }^{12}$ A visão dos professores sobre os processos de ensino/aprendizagem será apresentada em outro momento.

${ }^{13}$ Sobre os professores que atuam em cursos comunitários, ver Zago (2009).

${ }^{14} \mathrm{O}$ salário mínimo, em março de 2008, era de $\mathrm{R} \$ 415,00$ (quatrocentos e quinze reais).
} 
egressos do sistema público de educação, filhos de pais trabalhadores e estão inseridos no mercado de trabalho ou com expectativa de inserção. Entre os estudantes que responderam aos questionários, 22 estavam trabalhando no momento em que a pesquisa foi realizada (10 no mercado formal e 12 no informal); os outros 24 estavam desempregados. Maggie (2001) realiza uma pesquisa em pré-vestibulares comunitários organizados na baixada fluminense do Rio de Janeiro e apresenta uma caracterização equivalente àquela encontrada em Petrópolis. Ela diz que os pré-vestibulares do movimento Pré-Vestibular para Negros e Carentes (PVNC) são compostos, em sua maioria, por egressos de escolas públicas (cursos técnicos e/ou noturnos) com baixa renda familiar e sem tradição nos estudos universitários. Os vestibulandos são os primeiros de suas famílias a tentarem ingressar no ensino superior.

Entre os estudantes do curso analisado, quatro são oriundos de composições familiares em que algum dos membros possui formação de nível superior completa ou em curso. Há também sete famílias de origem em que o pai ou a mãe têm ensino médio completo. As outras 35 famílias são formadas por pais e mães ou por pais ou por mães com o ensino fundamental incompleto, completo, ou com o ensino médio incompleto. É possível afirmar, portanto, que a primeira opção pelo curso superior não ocorreu como tentativa de seguir tradições familiares relacionadas às profissões escolhidas. São famílias com baixo nível de escolarização, que não entendem porque os estudantes desejam continuar estudando depois de terem concluído o ensino médio, mas também não impedem que os jovens deem sequência a seus projetos de escolarização.

Quando perguntamos se a família apoiava a continuidade dos estudos, 35 responderam que sim, 5 disseram que não, 4 afirmaram que a família não se pronunciava e um não respondeu. A questão solicitava que os entrevistados justificassem suas respostas, mas 39 responderam apenas sim ou não. Entre os que justificaram (7 respostas ao todo), os argumentos contrários à manutenção dos estudos estão relacionados a expectativas familiares que excluem a escolarização de nível superior.

Uma estudante informou que seu cônjuge não gostaria que ela continuasse estudando, porque preferia que ela o ajudasse financeiramente. A fala do marido indica a valorização do trabalho em detrimento da ampliação dos estudos. Não existem, nesse caso, expectativas de que a formação universitária possa aumentar a renda familiar ou promover a mobilidade social. A preocupação apresentada se refere ao presente imediato, no qual questões financeiras são apresentadas como os principais problemas a serem enfrentados pelo casal.

A preocupação com o presente também foi citada por outra estudante, quando informou que sua família preferia que ela passasse a se preocupar mais com o presente e menos com o futuro. O futuro é percebido como lugar de incerteza, enquanto o presente é legitimado como espaço de possibilidade de existência e amadurecimento. A família entendia as preocupações com o futuro como pertinentes à adolescência, enquanto as 
atitudes relacionadas à manutenção do presente eram percebidas como sinônimo de maturidade.

A valorização do presente em oposição a expectativas futuras também aparece em outras falas. Uma entrevistada informou que sua família não se preocupa, porque acredita que o que ela fizer para seu futuro estará bem feito. A família entende que a estudante não deixou de se preocupar com o presente, o que permite que também pense no futuro. Outra entrevistada afirmou que a família não a apoiava, porque entendia que, como ela já sabia "alguma coisa", não precisava estudar. A escolarização dela superava, em muitos anos, aquela experimentada por seus familiares. Por isso, a vontade de permanecer estudando era vista com estranhamento, pois significava abrir mão da posição ocupada no mercado de trabalho e de um possível casamento.

Há também preocupações relacionadas à saída dos filhos de casa e, principalmente, da cidade para estudar. Não há universidades públicas em Petrópolis, o que obriga os estudantes a migrarem para cidades que ofereçam educação pública de terceiro grau. A distância entre Petrópolis e a cidade do Rio de Janeiro é de aproximadamente $80 \mathrm{~km}$. Migrar para o Rio de Janeiro pressupõe assumir os custos representados por aluguéis e outras contas ou pelas passagens dos ônibus que fazem o trajeto Petrópolis - Rio. Os egressos estabelecem estratégias para permanecerem no Rio de Janeiro, principalmente com a utilização de alojamentos universitários, mas ao entrarem no curso os estudantes não têm muita clareza sobre suas possibilidades de migração. Daí as dificuldades enfrentadas quando precisam explicar para as famílias como conseguirão sobreviver em outra cidade, sem emprego, parentes e ajuda financeira.

A preocupação das famílias é coerente, porque apenas cinco entrevistados pretendem prestar vestibular e pleitear bolsas nas universidades particulares de Petrópolis. Três desejam concorrer às vagas da Universidade Católica de Petrópolis e dois, às da Universidade Estácio de Sá. Entre os outros, 36 declararam que prestariam vestibular para um conjunto de universidades públicas presentes no Sudeste. Como a maioria dos estudantes pretende prestar dois ou mais vestibulares, agrupamos as universidades de acordo com o número de citações que receberam. As duas mais citadas foram a Universidade Federal do Rio de Janeiro (32 citações) e a Universidade do Estado do Rio de Janeiro (27). ${ }^{15}$ As outras universidades mencionadas foram: Universidade Federal de Juiz de Fora (18 citações), Universidade Federal Fluminense (12), Centro de Educação a Distância do Estado do Rio de Janeiro (4), Universidade Federal de Ouro Preto (2), Universidade Federal do Estado do Rio de Janeiro (2), Universidade Federal de Minas Gerais (3), Universidade Federal de Uberlândia (2) e Universidade Federal Rural do Rio de Janeiro (1).

A mesma pluralidade presente na escolha pelas universidades aparece na escolha pelas carreiras. Os estudantes optam por engenharias (6), medicina (4), psicologia (4), comunicação social (4), matemática (4), farmácia (2), arquitetura (2), história (2), letras (2), nutrição (2), biologia (2), administração (2), serviço social (2), química (1), economia (1),
${ }^{15}$ É importante salientar que a opção pela Universidade Federal do Rio de Janeiro (UFRJ) ou pela Universidade do Estado do Rio de Janeiro (Uerj) também ocorre por expectativas de inserção em redes de solidariedade já estabelecidas entre os egressos do pré-vestibular nas duas universidades, além do conhecimento do sistema de assistência estudantil desenvolvido em ambas, principalmente pela UFRJ, que disponibiliza alojamento. 
informática (1), museologia (1), ciências sociais (1), pedagogia (1), direito (1). Um estudante não escolheu.

As justificativas apresentadas para as escolhas profissionais não remetem a expectativas de atuação profissional ou a classificações sobre o cotidiano de trabalho dos indivíduos formados nas áreas destacadas. Há correlações entre apreço por algumas disciplinas estudadas na educação básica e sua relação com a carreira escolhida. Uma entrevistada, que deseja cursar biologia, afirmou que optou pelo curso porque é a matéria com a qual se identifica. Ela disse que gosta de natureza e de animais e, por isso, escolheu a área. Um estudante, que pretende cursar história, afirmou que escolheu o curso porque gosta da matéria. Outra, que pretendia cursar letras, ofereceu um depoimento mais detalhado em que apresenta suas representações sobre esse curso. Ela disse:

Porque eu gosto de literatura e português. Literatura é trabalhar com o sentimento e com a razão, ela me faz compreender melhor como o pensamento humano evoluiu desde a origem da humanidade até hoje; resumindo, literatura: pensar, sentir sonhar.

Outro depoimento, de uma estudante que desejava cursar jornalismo, sintetiza a correlação entre contato com disciplinas na educação básica e expectativas profissionais. Ela justificou seu desejo pelo curso:

Porque eu adoro português, geografia e história e este curso compreende as três matérias. Acho-me (sic) muito comunicativa e me preocupo muito em estar sempre antenada (sic) em economia e política nacional e internacional.

Há algumas regularidades nas narrativas apresentadas pelos estudantes. Parece possível indicar, a título de hipótese, que o contato com disciplinas no ensino fundamental e no médio cria expectativas relacionadas às profissões disponíveis no mercado e ao possível sucesso profissional. Dessa forma, um estudante que gosta de física pensa em cursar engenharia ou áreas correlatas; aqueles que gostam de língua portuguesa desejam cursar letras, jornalismo ou outras carreiras assemelhadas.

Essas correlações mostram o tipo de conhecimento relacionado às profissões de nível superior que os estudantes detêm. Eles percebem a necessidade de gostar de disciplinas escolares para exercer algumas ocupações, mas o cotidiano dos profissionais que as exercem parece desconhecido. As escolhas são orientadas pelo reconhecimento de que a habilidade com disciplinas escolares específicas pode ser um capital importante para a superação do vestibular e o desenvolvimento dos cursos escolhidos. Talvez seja possível explicar esse desconhecimento pela ausência de modelos próximos. Os estudantes não são filhos de famílias que exercem profissões de nível superior, portanto, não teriam como estabelecer um contato mais direto com o cotidiano de profissionais desse nível. Por outro lado, é possível perceber algumas representações sobre o lugar social das profissões e, em consequência, dos profissionais 
que as exercem. As profissões consideradas pelo senso comum como de menor prestígio são menos procuradas. No entanto, conforme Honorato (2005) já indicou, ocorrem metamorfoses no decorrer do "ano letivo" que fazem com que os estudantes adéquem seus projetos iniciais ao campo de possibilidades presente às vésperas do vestibular. Nesse momento, as carreiras de menor prestígio são privilegiadas e percebidas como caminho possível para entrada imediata no ensino superior.

É importante salientar que o ensino superior aparece no horizonte de possibilidades dos estudantes em um momento específico, posterior ao término da educação básica. Ao contrário das famílias de classe média, analisadas por Nogueira (2010), nas quais a noção de "parentocracia"16 explica longos projetos familiares de escolarização, nota-se que entre os estudantes entrevistados não havia expectativas semelhantes. A inserção na universidade ganha sentido em um momento específico de suas trajetórias, quando concluem o ensino médio e percebem que é possível dar sequência aos estudos. As famílias não construíram longos projetos de escolarização para os filhos, mas contribuem quando apoiam a decisão dos jovens, mesmo sem entender exatamente as implicações das escolhas realizadas.

Costa e Cunha (2007), em uma análise sobre as trajetórias escolares de universitários egressos do sistema público de educação, também identificam a presença de motivações pessoais para a continuidade dos estudos. Além da motivação individual, os jovens obtiveram apoio de familiares e de amigos, mesmo daqueles que não tinham nenhum contato com o ensino superior. A entrada na universidade é representada como uma novidade que mescla alegria, expectativas e incerteza e acaba por se consolidar como projeto coletivo.

Outro ponto referente às escolhas está relacionado com a visão que as famílias dos estudantes têm sobre as carreiras escolhidas. Eles não sofrem pressões familiares para a escolha das profissões que seguirão após a superação do vestibular. Ao contrário dos jovens analisados por Coelho (2007), a família não indica ou orienta as carreiras que devem ser seguidas. A autora realiza um estudo antropológico sobre as emoções manifestadas por vestibulandos de um curso pré-vestibular que atende, majoritariamente, aos filhos das classes médias e das elites econômicas da cidade do Rio de Janeiro. Os relatos dos estudantes expressam o tom imperativo utilizado por suas famílias para determinar a escolha de suas carreiras. Seus entrevistados desejam, principalmente, o curso de medicina e relatam tradições e projetos familiares de formação nessa área específica.

A ideia de projeto familiar de formação superior, presente nas entrevistas realizadas por Coelho (2007), não aparece no discurso dos estudantes aqui analisados. Eles chegam ao pré-vestibular com desejo de inserção no ensino superior, mas sem muita clareza sobre o que é necessário para a realização de suas expectativas. As famílias oferecem apoio, mas em alguns casos não têm clareza sobre o que exatamente estão apoiando. Uma estudante comentou que a família não era contra
${ }^{16}$ A autora classifica como "parentocracia" o conjunto de investimentos familiares - práticas de acompanhamento da vida escolar, ações de internalização dos estudos, estratégias de escolha de estabelecimentos de ensino - que contribuem para trajetórias de êxito entre estudantes pertencentes às classes médias. 
sua presença no curso, mas não se preocupava com os resultados do vestibular. Ela disse que, para os seus pais, o que ela fizesse com relação à sua formação "estava bom", porque as expectativas familiares de escolarização já tinham sido supridas com a conclusão do ensino médio.

\section{Considerações finais}

A análise das motivações para a escolha do pré-vestibular, das universidades e das carreiras pretendidas teve por objetivo indicar aspectos das trajetórias de egressos do sistema público de educação que decidem investir em projetos de escolarização de longa duração. O texto analisou as expectativas de jovens que não teriam, a princípio, projetos de escolarização de nível superior em seus destinos sociais. A tentativa de entrada na universidade, no caso específico dos estudantes analisados, depende de outras mudanças sem as quais o projeto não se torna viável. É necessário migrar, abrir mão da segurança proporcionada pela rede de relações de afinidade e parentesco presente na cidade natal e contar com outras redes estabelecidas por jovens que os antecederam no mesmo espaço de formação.

O curso analisado não possui estatísticas referentes ao número de egressos que obtiveram sucesso nos cursos superiores que escolheram. As turmas são flutuantes, o que dificulta qualquer tentativa de produção de dados quantitativos. No entanto, as observações dos participantes e as entrevistas já realizadas permitem afirmar que o curso, em 16 anos, aprovou estudantes para as melhores universidades do Brasil, mesmo antes das políticas compensatórias. Entender esses resultados permite refletir sobre as mudanças na distribuição de oportunidades educacionais de nível superior no Brasil e sobre as potencialidades presentes em movimentos sociais organizados com o objetivo de educar aqueles que já saíram da escola. Os dados indicam que, mesmo com pouco conhecimento sobre as universidades e as carreiras escolhidas, os estudantes estabelecem metas e estratégias para a formação de nível superior e contam com as redes de solidariedade estabelecidas no pré-vestibular.

\section{Referências bibliográficas}

ALVES, Fátima; FRANCO JÚNIOR, Francisco Creso; RIBEIRO, Luiz César de Queiroz. Segregação residencial e desigualdade escolar no Rio de Janeiro. In: RIBEIRO, Luiz César de Queiroz; KAZTMAN, Ruben (Org.). A cidade contra a escola: segregação urbana e desigualdades educacionais em grandes cidades da América Latina. Rio de Janeiro: Letra Capital, FAPERJ; Montevidéu, Uruguai: IPPES, 2008. Disponível em: <http://www.eure.cl/numero/a-cidade-contra-a-escola-segregacaourbana-e-desigualdades-educacionais-em-grandes-cidades-daamerica-latina-luiz-cesar-de-queiroz-ribeiro-ruben-kaztman/> . 
BOURDIEU, Pierre Felix. Escritos de Educação. Petrópolis: Vozes, 2001.

. O poder simbólico. Rio de Janeiro: Bertrand Brasil, 2004.

Juventude é apenas uma palavra. In: BOURDIEU, Pierre Felix.

Questões de sociologia. São Paulo: Marco Zero, 1983.

. A economia das trocas simbólicas. São Paulo: Perspectiva, 2003.

A reprodução. Rio de Janeiro: Francisco Alves, 1992.

BONAMINO, Alícia Maria Catalano; FRANCO, Francisco Creso. Avaliação e política educacional: o processo de institucionalização do Saeb.

Cadernos de Pesquisa, São Paulo, v. 108, p. 30-44, 1999.

CARVALHO, Marília Pinto de. Mau aluno, boa aluna?: como as professoras avaliam meninos e meninas. Revista Estudos Feministas [on-line], v. 9, n. 2, p. 554-574, 2001. Disponível em:

<http://dx.doi.org/10.1590/S0104-026X2001000200013>.

Sucesso e fracasso escolar: uma questão de gênero. Educação

e Pesquisa [on-line], v. 29, n. 1, p. 185-193, 2003. Disponível em:

<http://dx.doi.org/10.1590/S1517-97022003000100013>.

COELHO, Lídia Maria Teixeira Lima. Você tem medo de quê?

Um estudo socioantropológico acerca das emoções do vestibulando.

2007. Dissertação (Mestrado em Ciências Sociais) - Universidade do

Estado do Rio de Janeiro (UERJ), Rio de Janeiro, 2007.

COSTA, Márcio da. Prestígio e hierarquia escolar: estudo de caso sobre diferenças entre escolas em uma rede municipal. Revista Brasileira de Educação [on-line], Rio de Janeiro, v. 13, n. 39, p. 455-469, 2008.

Disponível em: <http://dx.doi.org/10.1590/S1413-

$24782008000300004>$.

COSTA, Márcio da; CUNHA, Marcela Brandão. Estudantes pobres recém-chegados ao ensino superior: o que pensam os próprios? Revista Contemporânea de Educação, v. 3, p. 7, 2007.

COSTA, Márcio da; KOSLINSKI, Mariane Campelo. Entre o mérito e a sorte: escola, presente e futuro na visão de estudantes do ensino fundamental do Rio de Janeiro. Revista Brasileira de Educação [online], Rio de Janeiro, v. 11, n. 31, p. 133-154, 2006. Disponível em: <http://dx.doi.org/10.1590/S1413-24782006000100010>.

COSTA, Márcio da; NOGUEIRA, Maria Alice. Introdução. Revista

Contemporânea de Educação, Rio de Janeiro, v. 4, n. 8, ago./dez. 2009. 
COSTA, Márcio da; SILVA, Graziella Moraes Dias da. Amor e desprezo: o velho caso entre Sociologia e Educação no âmbito do GT-14. Revista Brasileira de Educação [on-line], Rio de Janeiro, n. 22, p. 101-120, 2003. Disponível em: < http://dx.doi.org/10.1590/S1413$24782003000100010>$.

DANDURAND, Pierre; OLLIVIER, Émile. Os paradigmas perdidos: ensaio sobre a sociologia da educação e seu objeto. Teoria \& Educação, Porto Alegre, n. 3, p. 120-142, 1991.

ELIAS, Norbert; SCOTSON, John L. Os estabelecidos e os outsiders: sociologia das relações de poder a partir de uma pequena comunidade. Trad. Vera Ribeiro. Rio de Janeiro: Zahar, 2000.

FERREIRA, Walace. Educação e PVNC: uma análise sobre justiça social à luz de Honneth e Fraser e as ponderações estruturais de Bourdieu. 2007. Dissertação (Mestrado em Sociologia) - Universidade do Estado do Rio de Janeiro (Uerj), Rio de Janeiro, 2007.

FREITAG-ROUANET, Bárbara. Escola, Estado e sociedade. 6. ed. São Paulo: Cortez, 1987

GROPPO, Luís Antonio. Juventude: ensaios sobre sociologia e história das juventudes modernas. Rio de Janeiro: Difel, 2000.

HALBWACHS, Maurice. A memória coletiva. São Paulo: Vértice, 1990.

HONORATO, Gabriela de Souza. Estratégias coletivas em torno da formação universitária: status, igualdade e mobilidade entre desfavorecidos. 2005. Dissertação (Mestrado em Sociologia) Universidade Federal do Rio de Janeiro (UFRJ), Rio de Janeiro, 2005.

KEHL, Maria Rita. A Juventude como sinônimo da cultura. In: NOVAES, Roger; VANUCCI, Paulo (Org.). Juventude e sociedade: trabalho, educação, cultura e participação. São Paulo: Ed. Fundação Perseu Abramo, 2004.

KONSTANTOPOULOS, Spyros; BORMAN, Geoffrey D. Family background and school effects on student achievement: a multilevel analysis of the Coleman Data. Madison Teachers College Record, University of Wisconsin, v. 113, n. 1, p. 97-132, Jan. 2011. Disponível em: <http://www.tcrecord.org/Content.asp?ContentId=15989>.

LAVINAS, Lena; BARBOSA, Maria Ligia de Oliveira. Combater a pobreza estimulando a frequência escolar: o estudo de caso do Programa Bolsa-Escola do Recife. Dados [on-line], Rio de Janeiro, v. 43, n. 3, p. 447-477, 2000. Disponível em: < http://dx.doi.org/ 10.1590/S0011-52582000000300002>. 
MAGGIE, Yvonne. Os novos bacharéis: a experiência do pré-vestibular para negros e carentes. Revista Novos Estudos, Centro Brasileiro de Análise e Planejamento (Cebrap), São Paulo, v. 54, n. 59, p. 193-202, 2001.

MINAYO, Maria Cecília de Souza et al. Fala galera: juventude, cultura e cidadania na cidade do Rio de Janeiro. Rio de Janeiro: Garamond, 1999.

NOGUEIRA, Maria Alice. A Sociologia da Educação do final dos anos 60/ início dos anos 70: o nascimento do paradigma da reprodução.

Em Aberto, Brasília, v. 46, n. 46, p. 49-58, 1990.

Classes médias e escola: novas perspectivas de análise. Currículo sem Fronteiras, v. 10, n. 1, p. 213-231, jan./jun. 2010.

NOVAES, Regina C. Reyes. Juventudes cariocas: mediações, conflitos e encontros culturais. In: VIANNA, Hermano. Galeras cariocas: territórios de conflitos e encontros culturais. Rio de Janeiro: Ed. UFRJ, 2003.

PAIM, Eugenia. Forever young: a apropriação da imagem da juventude pela propaganda brasileira. Comunicações do Iser, Rio de Janeiro, v. 21, Edição Especial, 2002.

PAIS, José Machado. Culturas juvenis. Lisboa: Imprensa Nacional, Casa da Moeda, 2003.

RIBEIRO, Luiz César de Queiroz; KOSLINSKI, Mariane Campelo. Efeito metrópole e acesso às oportunidades educacionais. In: ENCONTRO ANUAL DA ANPOCS, 32., Caxambu, MG, 2008. [Trabalhos... GTO2: A metrópole e a questão social]. 2008. Disponível em: <http://www. observatoriodasmetropoles.ufrj.br/TrabalhoANPOCS2008.pdf $>$.

; ___ Efeito metrópole e acesso às oportunidades educacionais. EURE [on-line], Santiago, v. 35, n. 106, p. 101-129, 2009. Disponível em: <http://dx.doi.org/10.4067/

S0250-71612009000300006>.

ROCHA, Maria Sílvia Pinto de Moura Librandi da; PEROSA, Graziela Serroni. Notas etnográficas sobre a desigualdade educacional brasileira. Educação \& Sociedade [on-line], Campinas, v. 29, n. 103, p. 425-449, 2008. Disponível em: <http://dx.doi.org/10.1590/S010173302008000200007>.

ROSISTOLATO, Rodrigo Pereira da Rocha. Orientação sexual na escola: expressão dos sentimentos e construção da autoestima. Revista Brasileira de Estudos Pedagógicos, Brasília, v. 50, n. 225, p. 367-384, maio/ago. 2009a. 
ROSISTOLATO, Rodrigo Pereira da Rocha. Gênero e cotidiano escolar: dilemas e perspectivas da intervenção escolar na socialização afetivo-sexual dos adolescentes. Revista Estudos Feministas, Florianópolis, v. 17, n. 1, p. 11-30, ago. 2009b. Disponível em: < http://www.periodicos.ufsc.br/index.php/ref/issue/view/1191/showToc>.

SPOSITO, Marília Pinto. Algumas reflexões e muitas indagações sobre as relações entre juventude e escola no Brasil. In: ABRAMO, Helena Wendel; BRANCO, Pedro Paulo Martoni (Org.). Retratos da juventude brasileira. São Paulo: Instituto Cidadania, Fundação Editora Perseu Abramo, 2005.

SILVA, Graziella Moraes Dias da. Sociologia da sociologia da educação: caminhos e desafios de uma policy science no Brasil (1920-1979). Dissertação (Mestrado em Sociologia) - Universidade Federal do Rio de Janeiro (UFRJ), Rio de Janeiro. 2001.

SOARES, José Francisco; RIGOTTI, José Irineu Rangel; ANDRADE, Luciana Teixeira de. As desigualdades socioespaciais e o efeito das escolas públicas de Belo Horizonte. In: RIBEIRO, Luiz César de Queiroz; KAZTMAN, Ruben (Org.). A cidade contra a escola: segregação urbana e desigualdades educacionais em grandes cidades da América Latina. Rio de Janeiro: Letra Capital, Faperj; Montevidéu, Uruguai: IPPES, 2008.

TORRES, Haroldo da Gama et al. Educação na periferia de São Paulo: ou como pensar as desigualdades educacionais. In: RIBEIRO, Luiz César de Queiroz; KAZTMAN, Ruben (Org.). A cidade contra a escola: segregação urbana e desigualdades educacionais em grandes cidades da América Latina. Rio de Janeiro: Letra Capital, Faperj; Montevidéu, Uruguai: IPPES, 2008. Disponível em: < http://www.centrodametropole.org.br/pdf/2007/ Torres_Carpim_Gomes_e_Bichir_Educacao_final.pdf $>$.

VELHO, Gilberto. Individualismo e cultura: notas para uma antropologia da sociedade contemporânea. Rio de Janeiro: Jorge Zahar, 1999.

WILLMS, Jon Douglas. School composition and contextual effects on student outcomes. Teachers College Record, v. 112, n. 4, p. 1008-1037, apr. 2010 .

ZAGO, Nadir. Pré-vestibular e trabalho docente: caracterização social e mobilização. Revista Contemporânea de Educação, v. 4, p. 253-274, 2009.

Do acesso à permanência no ensino superior: percursos de estudantes universitários de camadas populares. Revista Brasileira de Educação [on-line], Rio de Janeiro, v. 11, n. 32, p. 226-237, maio/ago. 2006. Disponível em: <http://dx.doi.org/10.1590/S1413$24782006000200003>$. 
ZAGO, Nadir. Quando os dados contrariam as previsões estatísticas: os casos de êxito escolar nas camadas socialmente desfavorecidas. Paidéia [on-line], Ribeirão Preto, v. 10, n. 18, p. 70-80, 2000. Disponível em: <http://dx.doi.org/10.1590/S0103-863X2000000100007>.

Prolongamento da escolarização nos meios populares e as novas formas de desigualdades educacionais. In: PAIXAO, Lea Pinheiro; ZAGO, Nadir (Org.). Sociologia da Educação: pesquisa e realidade brasileira. Petrópolis: Vozes, 2007. p. 128-153.

Rodrigo Pereira da Rocha Rosistolato, doutor em ciências humanas (Antropologia) pela Universidade Federal do Rio de Janeiro (UFRJ), é professor do departamento de Fundamentos da Educação, da Faculdade de Educação da UFRJ.

rosistolato@yahoo.com.br

Jose Abdalla Helayël-Neto, PhD em Física pela International School for Advanced Studies in Trieste, é pesquisador titular III no Centro Brasileiro de Pesquisas Físicas (CBPF/MCT).

helayel@pq.cnpq.br

Marcel Duarte da Silva Xavier, licenciado em Matemática pela Universidade Federal Fluminense (UFF) atualmente desenvolve pesquisas de iniciação científica no Laboratório Nacional de Computação Científica (LNCC) na área de modelagem computacional.

marcelmat.uff@hotmail.com

Recebido em 12 de fevereiro de 2011.

Aprovado em 14 de setembro de 2011. 